\title{
The Antecedents and Consequences of Learned Helplessness in Work Life
}

\author{
Ozge Tayfur \\ Hacettepe University, Turkey \\ otayfur@hacettepe.edu.tr
}

\begin{abstract}
Technologies, processes and products are easily imitated in today's business world, so organizations can differentiate themselves from others only with their human capital. Helplessness, which may reflect itself as alienation, withdrawal, turnover intention is a serious problem that could prevent the adequate utilization of human capital. The overarching purpose of this study was to review "learned helplessness literature" with specific focus on helplessness in work context. This study, hopefully provided insights about why employees exhibit passive behaviors and apathy; in other words fall into helplessness even though they could initiate a change. In the first part, development of learned helplessness concept was explained together with initial models and experiments. After providing this background information, the individual and work-related antecedents of helplessness were listed. As part of antecedents, the impact of locus of control, gender, role stressors (i.e., workload, ambiguity) and organization structure was discussed briefly. In the third part, both organizational and individual consequences of helplessness were mentioned. Finally, suggestions were made to both practitioners and researchers in order to contribute advancement of theory and improvement of quality of work life.
\end{abstract}

Key Words: Learned helplessness, apathy, attributions, passivity, and stress

\section{Introduction}

Upon their birth to till their death, people strive to control environment and take advantage of it. Apathy and submissiveness are against human nature, which is oriented to control the things happening around and make sense of the world. If it is so, why do people comply with the wishes of their parents, supervisors, friends and authority figures although they believe that change is necessary? Why do people passively wait for someone to do something although they have the resources and capability to initiate a change? Answering these questions will shed light into why people become passive, apathetic and submissive in some cases and what remedies could be taken to solve motivation-related problems. People may become passive for various reasons. For example, lack of necessary abilities and resources could make people passive and accept the situation as it is. Sometimes, people become passive even though they have capability and opportunity to change adverse and unwanted situations. Believing that nothing can be done, and feeling lack of control over outcomes or events could induce passivity and apathetic behaviors. In the literature, passive behaviors and apathy arising from feelings of uncontrollability explained with the help of learned helplessness construct. Learned helplessness creates motivational, cognitive and emotional deficiencies, which make it difficult for people to learn new things, take initiative and cope with adversities. Helplessness should be regarded as a serious motivation problem to because it could hinder personal, societal, and organizational improvement. This paper aims to review the literature about learned helplessness to find answers for two important questions: (1) why do people fall into helplessness. (i.e., antecedents of helplessness), and (2) how does helplessness affect the behavior of people (i.e., consequences of helplessness). While answering these aforementioned questions, however, this paper focuses specifically on work-life and tries to uncover work-related antecedents and consequences of helplessness. This paper is believed to have both theoretical and practical implications. To the knowledge of the author, there has been limited number of studies addressing learned helplessness issue in work context. This study aims to contribute the relevant literature by providing comprehensive summary of previous studies and making suggestions for future research. Besides academia, practitioners may also benefit from this study. By understanding the factors inducing helplessness, managers and administrators could understand why employees remain silent and do not take initiative even though they realize the problems in the organization. Such an understanding could help managers when designing and implementing human resource systems. By reducing adverse conditions and increasing control over work outcomes, managers could decrease feelings of helplessness, had thereby better utilize human capital. 


\section{Literature Review}

The word "helpless" has been defined as "unable to take care of yourself or do things without the help of other people" in Oxford Advance Learner's Dictionary (2011). Parallel to this definition, learned helplessness, has been conceptualized as "the act of giving up trying as a result of consistent failure to be rewarded in life" in Collins Dictionary (2012); as "a condition in which a person suffers from a sense of powerlessness arising from a traumatic event or persistent failure to succeed." in Oxford Dictionary (2012). As seen from these definitions, a person becomes helpless after being subject to repeated failure, traumatic event or unable to get desired rewards and show this helplessness by giving up trying and feeling powerlessness. Similar definitions are encountered when literature about learned helplessness is reviewed as well. For example, Myers (2004) defines learned helplessness as "hopelessness and resignation learned when a human or an animal perceives no control over repeated bad events" (p.56). Similarly, Güler (2006) defines helplessness as "a notion of becoming passive after being exposed to stressors like repeated punishment, failure and adverse conditions and remaining passive even after environmental conditions make change possible" (p.26). As seen from these definitions, helplessness is a learned response, which manifests itself as resignation, withdrawal and passivity as a reaction to adverse conditions. In order to have a complete understanding of helplessness, it is necessary to understand historical development of the concept. The study conducted by Seligman and Maier (1967) laid the foundation of research on learned helplessness. Dogs, which had been unable to stop the electric shock at the beginning of the experiment, became passive and motionless as the time passed, even though they could easily escape from electric shock by jumping other side of the shuttle box (Seligman, 1992). Although every creature has an innate tendency to avoid pain or aversive situations, it is somewhat surprising that dogs did not show any effort to escape from shock. This unexpected result, which is apathy, passivity and lack of motivation to change aversive situation even though it is possible to do so, was named as "learned helplessness" and became one of the most widely studied topic in the literature. After Seligman and Maier (1967), many researchers conducted experiments about learned helplessness using different animals such as cats (e.g., Thomas \& Balter, 1974; cited in Güler, 2006), chickens (e.g., Job, 1987) and rats (e.g., Porsolt, Le Pichon \& Jalfre, 1977) and reached similar results. For example, rats, which were forced to swim in a narrow cylinder, first strived to swim, later gave up swimming, instead tried to remain on top of the water. The researchers interpreted the results with lack of controllability and claimed that animals became helpless because they learned that nothing could change the aversive situation they are in, so responding is futile. After demonstrating the existence of learned helplessness on animals, researchers directed their attention to human beings. Fosco and Geer (1971) divided participants into four groups; first group were given solvable problems, remaining groups were given both solvable and unsolvable problems. People in the second, third and fourth groups were assigned three, six and nine unsolvable problems respectively. To determine whether dealing with unsolvable problems and getting electric shock created helplessness, participants were given electric shock whenever they made mistakes.

At the end of the experiment, people who had to deal with more unsolvable problems found it difficult to solve easier (i.e., solvable) problems compared to other groups. According to researchers, people became unsuccessful because they felt themselves helpless about preventing electric shock, which had been given every time they gave wrong answers. Although this reasoning could be true, one cannot be sure about whether helplessness or the stress and frustration resulted from failure created performance deficiency. Experiments conducted with people should be designed more elaborately given the fact that the cognitive abilities of people are far more complex than those of animals. Considering the criticisms, Hiroto (1974) designed a more complex experiment to see whether failure to control undesirable and adverse situations cause helplessness among people. In this experiment, participants were divided into 3 groups: Helplessness, avoidance and control groups. In the first step, people in both helplessness and avoidance groups were instructed that they would hear disturbing sound that could only be stopped with pushing a button four times. People in the control group did nothing in this step. While people in the avoidance group stopped the sound following the instructions, people in the "helplessness group" could not stop it no matter what they did. In the second part of the experiment, people in three groups were again instructed that they would hear a disturbing voice, which could only be stopped by moving a lever from one side of the shuttle box to the other. At the end of the experiment, people in the helplessness group showed less effort to stop the disturbing sound, rather listened it passively compared to people in other groups. Hiroto (1974) explained this result with learned helplessness. Looking at the results of this experiment and other experiments (e.g., Gatchel \& Proctor, 1976; Miller \& Seligman, 1975; Miller, Seligman \& Kurlander, 1975; Klein \& Seligman, 1976; Klein, Fencil-Morse \& Seligman, 1976), it can be 
claimed if people are subject to adverse conditions for a long time and cannot change these situations with their actions, they perceive behavior-outcome independency and feel lack of control. This lack of control creates helplessness, which manifests itself passivity, lowered performance and motivation. Although findings of the experiments were in line with the findings of the animal experiments, these experiments were criticized both conceptually and methodologically and even accused of not measuring learned helplessness at all. According to Costello (1978), behavior-outcome independency does not always cause helplessness; sometimes having limited resources and opportunities cause passive behaviors, which is mistakenly interpreted as the sign of helplessness. In line with the arguments of Costello (1978), many studies (e.g., Roth \& Bootzin 1974; Roth \& Kubal, 1975; Tennen \& Eller, 1977) could not replicate the findings of Hiroto (1974), Gatchel, and Proctor (1976). In some studies, lack of control did not create helplessness, thus passive behaviors as expected; on the contrary, people who could not control outcomes with their behaviors showed greater effort and increased their performance. These conflicting results led researchers to develop models explaining the development of learned helplessness.

\section{Development of Learned Helplessness: Proposed Models}

Researchers tried to explain the findings of aforementioned experiments with various models. One of the earliest models was developed by Maier and Seligman (1976). In this model, people who cannot control the outcomes or the things happening around them feel cognitive, motivational (learning) and emotional deficits, which adversely affect their attitudes and behaviors. According to Maier and Seligman (1976), people who cannot obtain desired outcomes with their behaviors or avoid undesirable situations are not willing to show necessary behaviors when faced with similar conditions. Motivational deficits retard initiation of voluntary responses and are seen as consequence of expectation that responding is futile. Other than motivational problems, helplessness creates "cognitive deficits" and retards people's (or animal's) ability to learn that responding works. In other words, it makes it difficult for people to learn desired behaviors and realize that responding puts an end to unwanted situation. Finally, feeling oneself helpless creates "emotional problems" such as anxiety and depression. According to Maier and Seligman (1976), people start to feel themselves helpless when they learn that their behaviors and resulting outcomes are unrelated. Being aware of behavior-outcome independency creates cognitive problems, in other words make people believe that they cannot control outcomes. This perceived lack of control decreases motivation, later on causes emotional problems. Although this model explains the development and consequences of learned helplessness, it cannot explain why people perceiving lack of control over outcomes do not always feel themselves helpless and why they show greater effort. Realizing the limitation of Maier and Seligman's (1976) model, new model (known as "Reformulated Helplessness Model") was developed by Abramson, Seligman and Teasdale (1978), which again explains the development of learned helplessness, yet this time takes into account individual differences. Abramson et al. (1978) claims that perceived lack of control is necessary, yet not sufficient for the development of helplessness because people feeling lack of control over outcomes do not always fall into helpless and exhibit passive behaviors. According to researchers, major factor in the development of helplessness is "attribution /explanatory style", which refers to the manner in which person attribute causation to good and bad events". The model assumes that helplessness and depression are associated with pessimistic attribution style, which is characterized by explaining bad events with internal, stable and global causes. If a person explains the reasons for failure by using sentences like "I failed because I am unintelligent" (internality), "My intelligence level will affect me all the time" (stability) and "My intelligence will affect everything / I will fail in every circumstances" (globality), that person is assumed to have pessimistic attribution style, increasing vulnerability to helplessness.

Abramson et al (1978) mentions about 4 steps when explaining the development of helplessness. Initially, people become aware of behavior-outcome non-contingency, that is, they see no connection between behavior and outcomes. Then (second step), they perceive that behaviors and outcomes are connected to each other neither today nor in the past. In the third step, people make attributions regarding this noncontingency, that is, they explain why behaviors do not yield desired outcomes. Finally, they form an expectations concerning future behavior-outcome contingency and believe that behaviors would not be related to outcomes in the future, too. Like Maier and Seligman (1976), this model claims that helplessness results in motivational, emotional and cognitive deficits, which manifest themselves depression, anxiety, unwillingness and inability to learn. Unlike earlier learned helplessness models, however, this model distinguishes universal helplessness from personal helplessness. According to Abramson et al. (1978), when people believe that their responses as well as the responses of other people 
are unrelated to outcomes, they are prone to feel "universal helplessness". However, researchers claimed universal helplessness accounts for only a portion of helplessness construct; therefore, one needs to consider "personal helplessness" as well. Personal helplessness is argued to be observed when person know that there are responses, which would contingently produce desired outcomes, yet they are unable to show these responses even though they desired. In universal helplessness, persons make external attribution for outcomes meaning that they believe same outcomes are as likely to happen to themselves as to relevant others (Abramson et al., 1978); whereas in personal helplessness, people make internal attributions for outcomes and may believe undesired outcomes only happen to them. In addition to personal-universal helplessness distinction, one needs to be aware of global-specific helplessness distinction. When helplessness deficits occur in a broad range of situations, that is people show helplessness symptoms in different contexts, it is regarded as global helplessness; when the deficits occur in a narrow range of situations, it is regarded as specific helplessness. Global helplessness makes people believe that when they confront new situations the outcome will again be independent of their responses (Abramson et al., 1978); so responding and learning necessary responses are futile. Regardless of the type of helplessness (personal-universal; stable-unstable; global-specific helplessness), the symptoms of helplessness are observed when people expect that responses would be futile in obtaining desired outcomes (i.e. feel lack of controllability) and make pessimist attributions (Abramson et al., 1978) So far, the concept of learned helplessness and major models related to that were explained in detail to provide general background. Since the aim of this paper is to investigate employee helplessness, in the following sections, the meaning, antecedents and consequences of this construct are discussed considering workspecific factors.

Learned Helplessness in Work Context: Although it was not explicitly named, many scholars and researchers mentioned about the symptoms and consequences of employee helplessness in their articles and books. For example Marx (n.d) claimed that work conditions made people alienated from their job and led them exhibit passive behaviors, which were later regarded as manifestation of helplessness by some researchers (e.g., Martinko \& Gardner, 1982). The researchers who applied learned helplessness concept, which had already been one of the widely researched topics in psychology to work life was Martinko and Gardner (1982). According to these researchers, many problems in organizations especially the ones related to performance result from employees' beliefs that they cannot change outcomes with their efforts. Martinko and Gardner (1982) proposed an integrated model, which included both antecedents and consequences of helplessness in work life. The model has four dimensions, two of which compose of factors triggering helplessness (i.e., antecedents); others compose of consequences. In the first dimension, the researchers mentioned about stimulators, which could act as distal predictor of helplessness. Organization structure, performance appraisal system, reward system, the characteristics of leaders or managers and work-related factors such as task difficulty and structure were listed as "internal environment" simulators, whereas technology, social values, economic and political-legal conditions were listed as "external environment" simulators. These internal and external simulators determine whether employees succeed or fail, thus create success and failure experiences in people's mind. However, simulators and previous experiences are not enough for the development of helplessness. As in Abramson et al's model (1978), causal attributions (second dimension) are argued to be the key determinant of learned helplessness in Martinko and Gardner's model (1982). If an employee attributes his / her poor performance to a stable and internal dimension (i.e., lack of ability), s/he is more likely to become depressed, have lowered expectations for performance, and behave in a maladaptive way (Martinko \& Gardner, 1982), which are considered as signs of helplessness. However, unlike previous models, this model takes into account individual differences such as locus of control, achievement needs and gender. An employee with high achievement motivation or internal locus of control is thought to be more vulnerable to helplessness. Like Martinko and Gardner (1982), Carlson and Kacmar (1994) proposed a model explaining the development of helplessness in organizations. The researchers combined attribution theory with self-esteem construct and claimed whether individual and environmental factors create, helplessness depends on people's self-esteem. As in other models, researchers assert that people's attributions regarding success and failure play a key role on the development of helplessness.

According to the model, people who make internal and stable attributions for unfavorable outcomes (for failure) and external and unstable attributions for favorable outcomes (for success) are more vulnerable to feel themselves helpless. Albeit affecting helplessness largely, attributions are not regarded as sole determinant of the helplessness in the model. As indicated before, some individual and environmental factors are suggested to affect helplessness through their effect on performance. In the model, personal attribution style and personality factors are listed as individual factors; task characteristics, feedback, 
organizational support and role strain are listed as situational factors that could enhance or inhibit employee's performance, thus make people more or less vulnerable to helplessness. Considering the results of previous studies, the model claims that people scoring high on neuroticism, low on openness to experience, conscientiousness, extroversion and agreeableness would be less successful, which could increase their sense of helplessness. Unlike other models, the model proposed by Carlson and Kacmar (1994) claims that people having high self-esteem are less vulnerable to helplessness because of their tendency to explain success with internal and stable; failure with external and unstable factors. Although aforementioned models explain the development of helplessness with perceived lack of control and attribution style, they acknowledge the fact that some individual and work-related factors could affect attributions and control-related judgments of people, thus trigger the development of learned helplessness. These models provide integrated and comprehensive explanations regarding the development of employee helplessness, yet they have not been tested empirically so far. Though limited in number, there are studies investigating the effect of individual and organizational factors on helplessness in work-context. In the following parts, these factors are explained briefly.

Individual Factors Inducing Helplessness: Like other stress related syndromes, helplessness depends on the perceptions of people, meaning that sometimes work stressors manifest itself as helplessness yet sometimes the same work stressors do not affect people at all. Personality style, needs, priorities, gender, and age could affect the way people explain favorable and unfavorable outcomes, thus determine whether they would fall into helplessness, depression and stress. Despite the apparent role of individual factors on perception of stress and stress-related syndromes, limited number of studies investigated the role of individual difference variables on helplessness, especially in work context.

The Effect of Gender: So far, many researchers investigated the differences between males and females regarding the attribution style and tried to uncover whether males or females are more likely to make pessimistic attributions leading to helplessness. In one study (Kiefer, 1990), the women being subject to uncontrollable adverse conditions were found to make more pessimistic attributions (i.e., internal, universal and stable attributions for failure) and show symptoms of helplessness more compared to men. In another study (LeUnes, Nation \& Turley, 1980), researchers found that women dealing with unsolvable anagrams in the first phase of experiment were found to be less successful and motivated in the second phase compared to women dealing with solvable anagrams and not dealing with anagrams at all. Lack of motivation and performance decrement was not observed among male participants, which suggests that males are less vulnerable to helpless, when faced with uncontrollable adverse situations. The researchers explained male's resistance to helplessness with socialization process and claimed that males were more equipped to cope with frustrating situations because of the training they got their parents. Unlike many researchers claiming that women are more prone to feel themselves helpless, Baucom and Danker-Brown (1979) stated that the roles attributed to males and females by the society, not the mere sex made people feel helpless. According to researchers, people scoring on high on either masculinity or femininity are more likely to become helpless compared to people having both masculine and feminine tendencies. Some researchers (e.g., Radloff \& Monroe, 1978; cited in Baucom \& Danker-Brown, 1984) claimed that women show helplessness because they are more exposed to situations, which involve failure, lack of control and punishment. According to Seligman (1990), women are more prone to feel themselves helpless because of their tendency to dwell on their thoughts and explain unfavorable events and situations with pessimistic attribution style. It is noteworthy to mention that some studies (e.g., Dweck \& Llicht, 1980; Overton \& Meehan, 1982) reported conflicting results concerning the effect of gender on helplessness. For example, in one study, female students were found to exhibit less helplessness symptoms compared to male students. Similarly, Rozell, Gundersen and Tersptra (1998) found no difference between male and female university students with respect to helplessness they felt. Like Baucom and Danker-Brown (1979), researchers claimed that people having only feminine or masculine tendencies were more likely feel helplessness compared to people having androgen tendencies or genderneutral identity. Considering the conflicting results, it is hard to conclude that particular type of sex induces learned helplessness. Getting lower wages and salaries and having to deal with prejudgments, gender discrimination, and role conflicts could make women employees more vulnerable to helplessness. However, support given by coworkers, managers and family could alleviate the effects of adverse work conditions and lack of controllability, hence increase resilience of women employees.

The Effect of Personality \& Other Individual Factors: To the knowledge of the author, scant number of studies directly addresses the effect of personality on helplessness. However, many studies (e.g., Schaufeli \& Buunk, 2003; Armon, Shirom \& Melamed, 2012; O'Neill \& Xiao, 2010) revealed the effect of neuroticism 
and negative affectivity (e.g., Ormel \& Wohlfarth, 1991) on burnout, depression and stress, which had been shown to be associated with helplessness. In the literature, people scoring high on negative affectivity are argued to feel more stress, focus more on their failures and evaluate themselves more negatively (Watson \& Clark, 1984), which could create helplessness. In line with this argument, women with high scores on the neuroticism scale exhibited helplessness symptoms (i.e., took longer to solve anagrams) more than women with lower scores. However, the same result was not replicated for male participants, who seemed to be more affected by agreeableness. In that study, men scored higher on the agreeableness subscale solved anagrams faster than others; which indicates that agreeableness alleviates helplessness a certain extent (Cemalcılar, Canbeyli \& Sunar, 2003). Apart from neuroticism and negative affectivity, researchers argue that perfectionism, especially maladaptive one, could increase stress, hopelessness, and anxiety, which were found to be closely associated with helplessness in previous studies (e.g., Peterson, Maier, \& Seligman, 1993). In line with this argument, some of the sub dimensions of perfectionism such as concern for making mistake and getting approval of others were found to increase depression (e.g., Enns, Cox, Sareen \& Freeman, 2001; Bieling, Israeli \& Antony, 2004), hopelessness (e.g., Enns et al., 2001), anxiety (e.g., Hill et al., 2004) and self-blame (Dunkley et al., 2003). Besides, perfectionism was shown to increase depression, which is known to be one of the most prominent consequences of helplessness in considerable number of studies (e.g., Frost, Benton \& Dowrick, 1990; Hewitt \& Flett, 1990). In an exploratory study investigating the relationship between maladaptive perfectionism and helplessness, perfectionism was found to increase learned helplessness felt by physicians (Tayfur, 2011). As indicated before, individual attributions for the cause of unfavorable events could affect people's sense of controllability. Some individuals are more prone to explain their failures with stable, global and internal factors, which make them vulnerable to helplessness. Apart from personal attribution style, cognitive style could influence helplessness. For example, in one study (Brunstein \& Olbrich, 1985), action-oriented individuals unlike state-dependent ones increased their effort to control outcomes after being exposed to uncontrollable events and seemed to be more resistant to apathy, thereby helplessness. Moreover, people with an internal locus of control and low achievement motivation (e.g., Pittman \& Pitmann, 1982; Krantz et al., 1974; cited in Martinko \& Gardner, 1982) were found to be more vulnerable to helplessness in previous studies. Based on the review of literature, it can be concluded that individual characteristics like neuroticism, Type A personality make some people more prone to feel helplessness, yet these characteristics cannot serve as sole determinants of helplessness.

Organizational Factors Inducing Learned Helplessness: Although development of helplessness depends on perceptions, thereby individual factors, it is impossible to deny the role of organizational factors, which could reduce sense of accomplishment and control over work outcomes. Literature about work stress and burnout give important insights about organizationally induced helplessness. By leaving no room for decision-making and taking initiative, organizational structure, norms, procedures could reduce employees' sense of control, which in turn could make employees more vulnerable to helplessness. Employees of relatively centralized, bureaucratic organizations that rely on formal rules and policies often experience feelings of alienation and helplessness because inability to determine work methods and decide on work matters (i.e. lack of autonomy) creates perceptions of non-contingency between behavior-outcomes, which constitute the core of helplessness. Previous studies clearly demonstrated that lack of autonomy in organizations increased helplessness (e.g., Ashforth, 1989) and other stress syndromes like emotional exhaustion (e.g., Fernet, Austin, Trépanier \& Dussault, 2012).

Apart from organizational structure and procedures, role-related problems such as high workload, role conflict and ambiguity may play a role in development of helplessness. Previous studies (e.g., Abramis, 1994; Shepherd, Tashchian, \& Ridnour, 2011) showed the effects of role ambiguity and conflict on strain, stress and burnout, which are closed related to helplessness. Role ambiguity and conflict is argued to weaken effort-to-performance and performance-to-reward expectancies (Jackson \& Schuler, 1985; cited in Tubre \& Collins, 2000), which could reduce control over outcomes, thereby induce helplessness. Consistent with this argument, physicians and bank employees, feeling ambiguity regarding roles, responsibilities and expectations (scoring high on role ambiguity) scored high on helplessness scale in two different field studies (Tayfur, 2011). Recent study (Tayfur \& Arslan, 2012) also reported relationships among helplessness, time-related stressors and support such that high workload and workfamily conflict increased helplessness; while supervisor support alleviated the effects of workload and work-family conflict on helplessness. Organizations can induce helplessness, powerlessness and other strains by diminishing employees' sense of control. Although not tested empirically, Yuksel and Ozkiraz (2012) claimed that employees working in public sector could be vulnerable to helplessness for several reasons. The researchers stated that personnel systems, which rewards employees based on seniority rather than merit, bureaucratic organizational structure and lack of participation could increase feelings 
of helplessness. Although empirical analyses are limited in number, organizational factors that might induce helplessness could be listed by looking at the results of previous studies about stressor-strain relationships and propositions of learned helplessness models. These factors along with individual ones are summarized in Table 1.

\section{Table 1: Organizational \& Individual Factors Inducing Helplessness}

\begin{tabular}{|c|c|}
\hline Organizational Factors & Individual Factors \\
\hline \multicolumn{2}{|l|}{ Factors reducing sense of control: } \\
\hline 1) Highly centralized and formalized structure & 1) Pessimistic attribution style (explaining unfavorable \\
\hline 2) Tall hierarchy & outcomes with internal, stable and global factors; \\
\hline 3) Goal setting system not compatible with knowledge & favorable ones with external, unstable, specific factors) \\
\hline$\&$ abilities of employees & 2) Having maladaptive perfectionism \\
\hline 4) Performance appraisal system not linking effort to & 3) Having internal locus of control \\
\hline performance and performance-to-reward. & 4) Having low achievement motivation \\
\hline $\begin{array}{l}\text { 5) Demanding jobs (difficult \& complex tasks, jobs } \\
\text { requiring to meet deadlines) }\end{array}$ & 5) Scoring high on neuroticism \& negative affectivity \\
\hline $\begin{array}{l}\text { 6) Inappropriate leadership style (dogmatic, petty } \\
\text { tyranny leadership) }\end{array}$ & \\
\hline 7) Lack of empowerment and participatory leadership & \\
\hline 8) Sudden, continuous technological changes & \\
\hline Factors increasing strain, thereby helplessness & \\
\hline High workload & \\
\hline Role ambiguity, role conflict & \\
\hline Unmet expectations & \\
\hline Lack of alternatives for finding jobs and promotion & \\
\hline
\end{tabular}

Consequences of Learned Helplessness: Researchers generally make propositions about the consequences of helplessness by looking at the results of previous studies about depression and hopelessness, which are known to be closely associated with helplessness. However, majority of these propositions were not tested empirically. Despite this shortcoming, the consequences of helplessness could be classified under three headings: Physical, psychological and organizational consequences. Physiological symptoms of helplessness are listed as lack of serotonin, norepinefrin, imsomnia and reduced appetite (Peterson et al., 1993). Helplessness is thought to affect physical and mental health by creating neurochemicial changes in people. Apart from these physical problems, helplessness is argued to cause psychological problems such as depression, aggression, anger, anxiety, apathy, shame and hostility (Seligman, 1992; Peterson et al., 1993, Martinko \& Gardner, 1982). Previous studies (e.g., McMullen \& Kratz, 1988; Tayfur, 2011; Wortman \& Brehm, 1975) found helplessness to be associated with increased emotional exhaustion, and depersonalization. Besides that, pessimistic attributional style, which is a characteristic of learned helplessness, is argued to induce self-directed counterproductive behaviors such as drug abuse and alcoholism (Mackey \& Martinko, 2012).

In addition to individual consequences, helplessness creates problems in organizations. In one of the earlier models (i.e., Martinko \& Gardner, 1982) performance decline, absenteeism, passiveness, turnover intention, and withdrawal were listed as major organizational outcomes of helplessness. In another model (Campbell \& Martinko, 1998), helplessness is argued to increase employees' tendency to make mistakes and exhibit passive behaviors, make them reluctant to speak up and challenge other people. The findings of a recent study (Tayfur, 2011) were found to be consistent with these models. The study reported relationship between helplessness and reluctance to report unethical practices. In addition to increasing passivity and withdrawal, helplessness was also found to reduce work adjustment of newcomers (e.g., Ashforth \& Saks, 2000), performance of sales agents (e.g., Schulman, 1999; Seligman \& Schulman, 1986) and intention to stay in the organization (e.g., Seligman \& Schulman, 1986). Employees feeling high level of helplessness and powerlessness also experienced high level of alienation (Ashforth, 1989). Although not tested empirically, helplessness is argued to create number of problems in public sector such as working unwillingly, doing tasks perfunctorily, regarding new applications and innovative actions unnecessary and showing unnecessary loyalty to traditional even old-fashioned methods (Yuksel \& Ozkiraz, 2012). In sum, helplessness gives damage to physical and mental health of employees and inhibits personal and organizational development by inducing passivity, withdrawal and hopelessness. 


\section{Suggestions for Future Research}

Although there are voluminous, number of studies investigating learned helplessness, majority of them were conducted in laboratories, which casts doubts about the generalizability of the findings to real life. Scant number of field studies investigated the consequences of helplessness such as performance inhibition and passive behaviors without focusing solely on work-context. Although they are contributing the literature, many of the articles written about employee helplessness are theoretical in nature. These articles suggest models and propositions explaining the antecedents and consequences of helplessness, which have not been tested empirically, yet. Therefore, studies investigating the direct and indirect effects of work-stressors and individual factors are needed. Job Demand-Resources Theory could be a good starting point for pinpointing work-related antecedents of helplessness. Considering the detrimental effects of high workload, work-family conflict, role ambiguity and conflict on employee's wellbeing, it is reasonable to expect that these work stressors would increase helplessness felt by employees. Leadership style of managers could also influence employees' well-being, thus helplessness. Managers who do not give necessary support and allow employee participation and initiation could cause employees to lose sense of control, which in turn could increase symptoms of helplessness such as passivity and apathy. Therefore, relationship between helplessness and leadership styles such as autocratic, empowering, or dogmatic leadership is a good avenue for research. Studies conducted so far focused on performance deficiencies; yet there could be other consequences of helplessness. The relationship between helplessness and important work outcomes such as turnover intentions, job satisfaction, and cynicism is also worth attention. Lack of controllability and resulting helplessness could manifest itself as decreased self-esteem, career identification and organizational commitment, increased cynicism toward administration, coworkers and even customers. More importantly, feeling lack of control over outcomes could make reluctant to talk about problems, take initiation to solve them and even report unethical activities to people authority. Looking at the relationship between helplessness and some behaviors such as whistle blowing, and remaining silent could be invaluable for the development of helplessness literature. As a counterpart to learned helplessness, the future research on learned hopefulness hold promise for understanding employee behaviors. As suggested by Zimmerman (1990), researchers may shift their focus from the negative consequences of uncontrollability and pessimistic attributions to positive consequences of successful efforts to exert control. Instead of looking at dark side, researchers could look at positive side by revealing what induces people to work harder and not give up even the possibility of failure is high. Last but not the least; researchers could focus on the relationship between helplessness and culture. The majority of the research on helplessness has been conducted with people of Western societies, who are argued to attach more importance to personal agency and control, therefore could be more vulnerable to helplessness than people of Eastern societies. Although it cannot be claimed that helplessness is not observed in Eastern cultures /societies, it can argued that the magnitude and impact of helplessness may not high in these cultures. Researchers should investigate whether helplessness differs from one culture to another.

Suggestions for Practitioners: Helplessness is a learned response, which could be unlearned thus be prevented. For example, Abramson et al (1978) suggest several strategies for preventing the development of helplessness or least reduce the effect of it. One strategy is to change the estimated probability of the relevant event's occurrence. In this strategy, practitioners are suggested to reduce estimated likelihood for aversive outcomes and increase estimated likelihood for desired outcomes. Managers could implement this strategy by placing people to correct positions considering their knowledge, skills and abilities, implementing job placement for employees experiencing repeated failures and providing necessary resources and support to increase employees' chances of being successful. Second strategy for reducing helplessness could be making highly preferred outcomes less preferred, in other words, reducing expectations regarding outcomes. Managers could implement this strategy by reframing the importance of success and failure. By setting realistic goals to employees, managers could prevent employees from aiming to reach stars. SMART (specific, measurable, attainable, relevant, timebounded), goals could increase chances of success, at least prevent employees from wanting impossible. Also, by making employees believe that failure is not end of their career or world, managers could reshape perceptions regarding failure. Providing constructive feedback and showing role models, who once failed yet currently successful could be tactics for reducing helplessness. Third strategy that could be implemented involves "changing expectation from uncontrollability to controllability" (Abramson et al., 1978). 
Employees could be made more equipped by sending them to training programs, which provides necessary knowledge, skills and abilities for task accomplishment. With time and stress management trainings, the effects of work-related stressor such as work-family interference, work overload and role conflict could be alleviated and employees could be made more resilient in face of adversities. I believe that helplessness felt by employees could be lessened, if not eliminated with sound organizational interventions. Policies and interventions taken to reduce lack of controllability and pessimistic attributions, which are two prominent causes of helplessness, could solve helplessness, thus many motivation problems. First, resource allocation should be done properly and fairly so that every employee has enough resources for being successful. Task accomplishment may change employee's attributions for success, self-worth and their resilience for failures. Secondly, training needs of the employees should be satisfied because adequate training could enhance employee's coping skills and provide them necessary knowledge, skills and abilities, which could reduce their sense of uncontrollability. Thirdly, premises of Expectancy Theory should be taken into account. Managers should tie effort to performance (expectancy) and performance to desire outcomes (instrumentality) by providing employees adequate work conditions, ensuring person-job fit and designing performance-appraisal system and feedback systems, which recognize and reward outstanding performance immediately. Learned helplessness is a serious, yet solvable problem. By changing employees' perceptions about controllability and devising sound human resource policies, employees could become more resilient to adversities and have necessary knowledge, skills, abilities and motivation to tackle with problems.

\section{References}

Abramis, D. J. (1994). Work role ambiguity, job satisfaction, and job performance: Meta-analysis and review. Psychological Reports, 75(3f), 1411-1433.

Abramson, L. Y., Seligman, M. P. \& Teasdale, J. D. (1978). Learned helplessness in human: critique and reformulation. Journal of Abnormal Psychology, 87(1), 49-74.

Armon, G., Shirom, A. \& Melamed, S. (2012). The big five personality factors as predictors of changes across time in burnout and its facets. Journal of Personality, 80(2), 403-427.

Ashforth, B. E. (1989). The experience of powerlessness in organizations. Organizational Behavior and Decision Processes, 43(2), 207-242.

Ashforth, B. E. \& Saks, A. M. (2000). Personal control in organizations: A longitudinal investigation with newcomers. Human Relations, 53(3), 311-339.

Baucom, D. H. \& Danker-Brown, P. (1979). Influence of sex roles on the development of learned helplessness. Journal of Consulting and Clinical Psychology, 47 (5), 928-936.

Baucom, D. H. \& Danker-Brown, P. (1984). Sex role identity and sex stereotyped tasks in the development of learned helplessness in women. Journal of Personality and Social Psychology , 46 (2), 422-430.

Bieling, P. J., Israeli, A. L. \& Antony, M. M. (2004). Is perfectionism good, bad, or both? Examining models of the perfectionism construct. Personality and Individual Differences, 36(6), 1373-1385.

Brunstein, J. C. \& Olbrich, E. (1985). Personal helplessness and action control: Analysis of achievement related cognitions, self-assessments, and performance. Journal of Personality and Social Psychology, 48(6), 1540-1551.

Campbell, C. R. \& Martinko, M. J. (1998). An integrative attributional perspective of empowerment and learned helplessnes: A multimethod field study. Journal of Management, 24(2), 173-200.

Carlson, D. S. \& Kacmar, K. M. (1994). Learned helplessness as a predictor of employee outcomes: An applied model. Human Resource Management Review, 4(3), 235-256.

Cemalcılar, Z., Canbeyli, R. \& Sunar, D.(2003). Learned helplessness, theraphy and personality traits: An experimental study. The Journal of Social Psychology,143(1),65-81.

Costello, C. G. (1978). A critical review of Seligman's laboratory experiments on learned helplessness and depression in humans. Journal of Abnormal Psychology, 87(1), 21-31.

Dunkley, D. M., Zuroff, D. C. \& Blankstein, K. R. (2003). Self-critical perfectionism and daily affect: Dispositional and situational influences on stress and coping. Journal of Personality and Social Psychology, 84(1), 234-252.

Dweck, C. \& Llicht, B. (1980). Learned helplessness and intellectual achievement. In J. Garber, \& M.E.P. Seligman Human Helplessness: Theory and application. New York: Academic Press.

Enns, M. W., Cox, B. J., Sareen, J. \& Freeman, P. (2001). Adaptive and maladaptive perfectionism in medical students: A longitudinal investigation. Medical Education, 35(11), 1034-1042.

Fernet, C., Austin, S., Trépanier, S. G. \& Dussault, M. (2012). How do job characteristics contribute to burnout? Exploring the distinct mediating roles of perceived autonomy, competence, and relatedness. European Journal of Work and Organizational Psychology, 1-31.ifirst article. 
Fosco, E. \& Geer, J. H. (1971). Effects of gaining control over aversive stimuli after differing amounts of no control. Psychological Reports , 29(3), 1153-1154.

Frost, R. O., Benton, N. \& Dowrick, P. W. (1990). Self evaluations, videotape review and dysphoria. Journal of Social and Clinical Psychology, 9(3), 367-374.

Gatchel, R. J. \& Proctor, J. D. (1976). Physiological correlates of learned helplessness in man. Journal of Abnormal Psychology, 85(1), 27-34.

Güler, B. K. (2006). Çalışma Hayatında Öğrenilmiş Çaresizlik. Ankara: Liberte Yayınları.

Helplessness (2011). In Oxford Advance Learner's Dictionary online. Retrieved from http://oald8.oxfordlearnersdictionaries.com/dictionary/helplessness\#helpless.

Hewitt, P. L. \& Flett, G. L. (1990). Perfectionism and depression: A multidimensional analysis. Journal of Social Behavior and Personality, 5(5), 423-438.

Hill, R. W., Huelsman, T. J., Furr, R. M., Kibler, J., Vicente, B. B. \& Kennedy, C. (2004). A new measure of perfectionism: The Perfectionism Inventory. Journal of Personality Assessment, 82(1), 80-91.

Hiroto, D. S. (1974). Locus of control and learned helplessness. Journal of Experimental Psychology, 102(2), 187-193.

Job, R. F. (1987). Learned helplessness in chickens. Animal Learning \& Behavior, 15(3), 347-350.

Kiefer, L. F. (1990). Learned helplessness: A factor in women's depression. Journal of Women and Social Work, 5(1), 21-31.

Klein, D. C. \& Seligman, M. E. P. (1976). Reversal of performance deficits and perceptual deficits in learned helplessness and depression. Journal of Abnormal Psychology, 85(1), 11-26.

Klein, D. C., Fencil-Morse, E. \& Seligman, M. E. (1976). Learned helplessness, depression and, the attribution of failure. Journal of Personality and Social Psychology, 33(5), 508-516.

Learned helplessness. (2012). In Collins English Dictionary. Retrieved from http://www.collinsdictionary.com/dictionary/english/learned-helplessness.

Learned helplessness. (2012). In Oxford Dictionary online. Retrieved from http://oxforddictionaries.com/definition/learned\%2Bhelplessness?q=learned+helplessness.

LeUnes, A. D., Nation, J. R. \& Turley, N. M. (1980). Male-female performance in learned helplessness. The Journal of Psychology, 104(2), 225-258.

Mackey, J. \& Martinko, M. J. (2012). The role of gender and attributional style in counterproductive aggressive work behaviors. In S.Fox \& T.R.Lituchy, Gender and Dysfuctional Workplace, Cheltenham, UK, Edward Elgar Publishing Limited.

Maier, S. F. \& Seligman, M. (1976). Learned helplessness: Theory and evidence. Journal of Experinental Psychology: General, 105(1), 3-46.

Marx, K. (2011). The economic and philosophical manuscripts. Retrieved from Marks/Engels Works: http://www.marxists.org/archive/marx/works/1844/epm/index.htm, July 9th, 2011.

Martinko, M. J. \& Gardner, W. L. (1982). Learned helplessness: An alternative explanation on performance deficits. Academy of Management Review, 7(2), 195-204.

McMullen, M. B. \& Krantz, M. (1988). Burnout in day care workers: The effects of learned helplessness and self esteem. Child \& Youth Care Quarterly, 17(4), 275-280.

Miller, W. R. \& Seligman, M. E. (1975). Depression and learned helplessness in man. Journal of Abnormal Psychology, 84(3), 228-238.

Miller, W. R., Seligman, M. E. \& Kurlander, H. M. (1975). Learned helplessnes, depression and anxiety. Journal of Nervous and Mental Disease, 161(5), 347-357.

Myers, D. G. (2004). Exploring Social Psychology. Third Edition. New York: McGraw-Hill.

O’Neill, J. W. \& Xiao, Q. (2010). Effects of organizational/occupational characteristics and personality traits on hotel manager emotional exhaustion. International Journal of Hospitality Management, 29(4), 652-658.

Ormel, J. \& Wohlfarth, T. (1991). How neuroticism, long-term difficulties and life situation change influence psychological distress: A longitudinal model. Journal of Personality and Social Psychology, 60(5), 744-755.

Overton, W. \& Meehan, A. (1982). Individual difference in formal operational thought: Sex role and learned helplessness. Child Development, 53(6), 1536-1543.

Peterson, C., Maier, S. F. \& Seligman, M. E. (1993). Learned helplessness: A theory for the age of personal control. New York: Oxford Press.

Porsolt, R. D., Le Pichon, M. \& Jalfre, M. (1977). Depression: A new animal model sensitive to antidepressant treatment. Nature, 266 (5604), 730-732.

Roth, S. \& Bootzin, R. R. (1974). Th effects of experiementally induced expectancies of external control: An investigation of learned helplessness. Journal of Personality and Social Psychology, 29(2), 253264. 
Roth, S. \& Kubal, L. (1975). Effects of noncontingent reinforcement on tasks of differing importance: Facilitation and learned helplessness. Journal of Personality and Social Psychology, 32(4), 680691.

Rozell, E. J., Gunderson, D. E. \& Terpstra, D. E. (1998). Gender differences in the factors affecting helpless behavior and performance. Journal of Social Behavior and Personality, 13(2), 265-280.

Schaufeli, W. B. \& Buunk, B. P. (2003). Burnout: An overview of 25 years of research in theorizing. In M. J. Schabracq, J. A. Winnubst, \& C. L. Cooper, The handbook of work and health psychology. Chichester: Wiley

Schulman, P. (1999). Applying learned optimism to increase sales productivity. Journal of Personal Selling and Sales Management, 19(1), 31-37.

Seligman, M. E. P.(1990). Learned Optimism. New York: NY: Pocket Books.

Seligman, M. E. P. (1992). Helplessness: On depression, development, and death. A Series of Psychology Books. New York: W. H. Freeman Publishing.

Seligman, M. E. P. \& Schulman, P. (1986). Explanatory style as a predictor of productivitiy and quiting among life insurance sales agents. Journal of Personality and Social Psychology, 50(4), 832-838.

Seligman, M. E. P. \& Maier, S. F. (1967). Failure to escape traumatic shock. Journal of Experimental Psychology, 74(1), 1-9.

Shepperd, C. D., Tashchian, A. \& Ridnour, R. E. (2011). An investigation of the job burnout syndrome in personal selling. Journal of Personal Selling \& Sales Management, 31(4), 397-409.

Tayfur, 0. (2011). Çalışma hayatında öğrenilmiş çaresizlik ve tükenmişliğin nedenleri ve sonuçları üzerine bir çalışma. [A study on antecedents and consequences of learned helplessness and burnout in work life], Unpublished PhD Dissertation. Ankara, Turkey.

Tayfur, O. \& Arslan, M. (2012). The alleviating effect of perceived supervisor support on workload, workfamily conflict \& learned helplessness. Mediterranean Journal of Social Sciences, 3(6), 229-236.

Tennen, H. \& Eller, S. J. (1977). Attributional components of learned helplessness and facilitation. Journal of Personality and Social Psychology, 35(4), 265-271.

Tubre, T. \& Collins, J. (2000). Jackson and Schuler (1985) revisited: a meta-analysis of the relationships between role ambiguity, role conflict, and job performance. Journal of Management, 26(1), 155169.

Watson, D. \& Clark, L. A. (1984). Negative affectivity: The disposition to experience aversive emotional states. Psychological Bulletin, 96(3), 465-490.

Wortman, C. M. \& Brehm, J. W. (1975). Response to uncontrollable outcomes: An integration of reactance theory and the learned helplessness model. In L. Berkowitz. Advances in experimental social psychology (8). New York: Academic Press.

Yuksel, F. \& Ozkiraz, A. (2012). The main problem of Turkish public administation: Learned helplessness. African Journal of Business Management, 6(4), 1214-1221.

Zimmerman, M. A. (1990). Toward a theory of learned resourcefulness: A structural model analysis of participation and empowerment. Journal of Research in Personality, 24(1),71-86. 